Volume 9, No.3, May - June 2020

International Journal of Advanced Trends in Computer Science and Engineering

Available Online at http://www.warse.org/IJATCSE/static/pdf/file/ijatcse131932020.pdf

https://doi.org/10.30534/ijatcse/2020/131932020

\title{
Role of Mobile Communication with Emerging Technology in COVID'19
}

\author{
Reena Bhavya ${ }^{1}$, Saurabh Sambhav ${ }^{2}$ \\ ${ }^{1}$ Student, Department of Computer Science Engineering, Amity University, Patna, India. \\ ${ }^{2}$ Assistant Professor, Amity School of Engineering and Technology, Amity University, Patna, India- 801503. \\ ssambhav.iit@gmail.com, ORCID ID- https://orcid.org/0000-0001-6591-5584
}

\begin{abstract}
This study shows impact of technology for communication in our day to day life and how our system welcomed emerging technology during this pandemic. Corona virus is causing serious health hazards all over the world causing many deaths and infections. It's not an ordinary disease, as it spread very easily due to number of factors like handshake or touching infectious surface and its complete treatment has also became a challenge for doctors as vaccine is not there and proper equipment are also not there because number of COVID -19 patients are very large. As its further spread is nearly impossible to stop but we can control the spread of infection by getting least socialized. Government of many countries all over the world has announced complete lockdown ordering all institutes, shopping malls, transports and organization to be closed so that social gathering could be avoided as far as possible, in this case our mobile phones are becoming our service provider. Mobile phone and its applications has become the life savior indirectly as whatever we used to do before, is possible to do now also like banking, ordering groceries, video calls, news, job, education and many more. Our technologies like artificial intelligence, big data analysis, robotics, drone, contact tracking, 5G, 3D printers etc., are helping to analyze and control the spread also making the treatment fast as well as effective. This study also focusing on connection with $5 \mathrm{G}$ communication and how this is helping our life along with mobile computing.
\end{abstract}

Key words: Artificial intelligence, 3D printers, Robots, Lockdown, Online education, 5G.

\section{INTRODUCTION}

COVID-19 is a pandemic which is affecting people's life at a large scale all over the world. It is caused by a family of viruses known as corona virus shown in figure 1 [1]. This virus is life threatening and has dreadfully caused many deaths. This virus is transferred from one person to another and thus it has affected the whole world in a very short period of time [2]. Till now there are more than 6.2 million corona active cases and more than 3.7 lakhs of people have died due to this virus all over the world. Its symptoms start from common cold to SARS and MERS which are life threatening. Its outbreak started from Chinese city Wuhan [3]. Many countries all over the world have announced lockdown for the safety of its people. The situation is worse, we have never seen any pandemic like this causing deaths rapidly [4]. All transports, companies, schools are closed. Social distancing and stay at home is best solution to avoid the further spread of this virus. Due to lockdown we are helpless and have no choice to stay inside our home for the sake of our safety but due to this system of education, economy, religion, various organizations, marketing, etc. everything has stopped as no one can is available to give their service.

As we know that the pandemic caused due to corona viruses is spreading worldwide causing many death and infecting people at a large scale. This deadly corona virus is transferred one person to other person even through basic social gestures like face to face communication, handshake, or touching infected surface etc. So to avoid more infections and deaths lockdown has been announced in many countries all over the world [5].

Now a day the main concern throughout the whole world is how to stop the spread of viruses? How to cure the affected people when the equipment are less? How to test the infected person out of big crowd where the testing kits are limited? How to provide basic life sustaining services to people locked inside their houses? How to regulate education of students? What about employment? How to collect Funds and regulate basic operation for poor's and covid-19 patients?

We can say that this deadly pandemic has put a big question mark on the system of whole world but no matter what's the level of challenges we are facing these days due to COVID-19 we are blessed to born in 21st century, which has witnessed many evolution and enhancement in science and technology. 


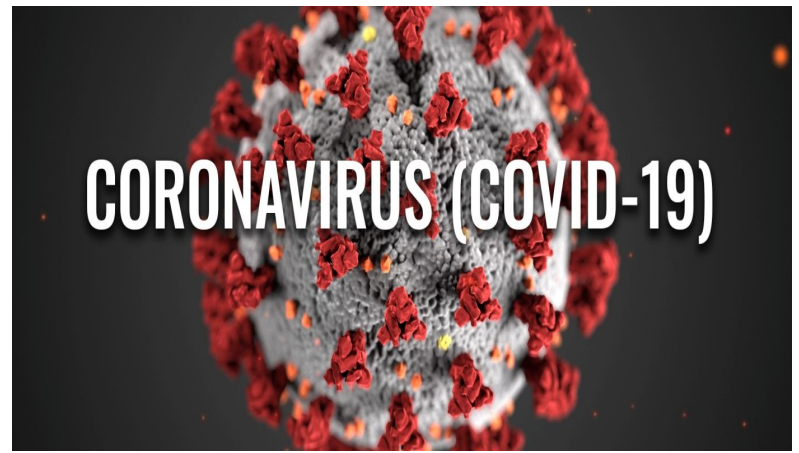

Figure 1: COVID 19 (Coronavirus) [1]

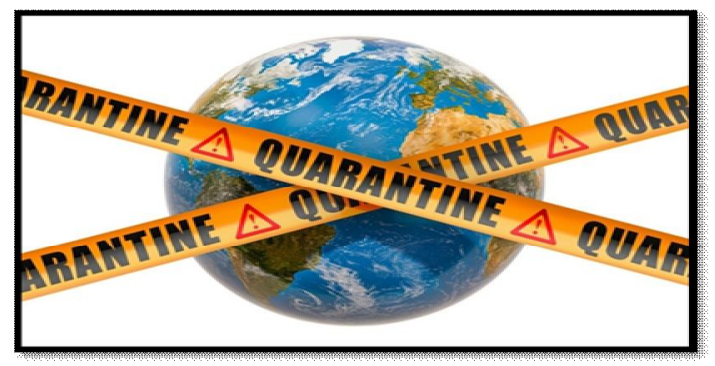

Figure 2: Image representing situation [5]

If we talk about role of mobile communication and technology in COVID-19, one thing which we can easily realize is that in this situation also where everything could be nearly impossible, we are able to stand against deadly corona virus. We are able to regulate our jobs, education, money transfer, shopping, social gathering on phone, and the most important thing is that our learning has not stopped i.e., we are able to utilize our free time in learning various skills like cooking, practicing foreign languages, games, painting, dancing and many more. All these things are possible due to mobile communication and technology. It is playing a great role not only in making our life sustainable but nearly as before [6]. Can we imagine our life during lockdown shown in figure 2 without mobile and other technologies? What could have happened if time goes two centauries back? We can easily realize that without these technologies we could not be able to fight this war against deadly virus and may have died due to hunger or infection.

So mobile and technologies are something like life savior during COVID-19 [7]. They are helping in regulating basic life functionalities and avoiding spread of virus and killing it, it is also helpful in precaution plus cure. Along with India many other countries are developing various kinds of technologies which are very helpful in this situation like 3D printer to print ventilators for treatment of corona victims [8], big data [9] for workers, employee, patients etc., artificial intelligence based orthopedics [10-11] securities in health care industries and robots operating many human jobs [12] etc.

\section{MOBILE COMMUNICATION AND ITS APPLICATIONS}

As COVID-19 is spreading very rapidly all over the world affecting many people's live at risk. It has killed more than 3.72 lakhs of people all over the world. The pandemic has not stopped yet and is continuously killing people rapidly. To stop the spread and deaths whole world is using their technologies at best level to regulate the society with minimum risk. Some of the technologies which are being used are:

\subsection{Healthcare Applications}

A. Artificial Intelligence and data analysis: It is very important to avoid more spread of infections and deaths. BlueDot's is a Canadian startup, it has developed an Artificial Intelligence based algorithm which analyzes all government news, report and social media for tracking COVID-19

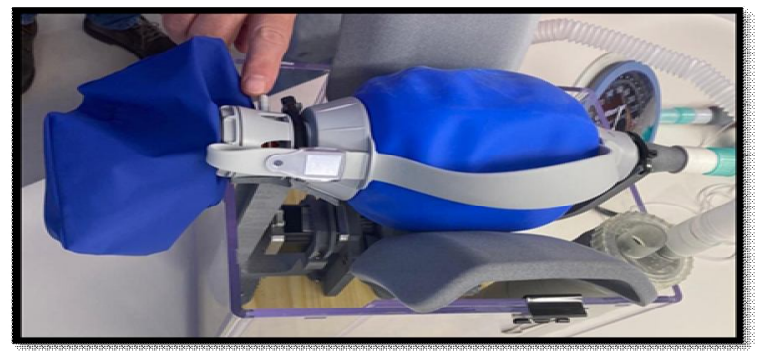

Figure 3: Artificial Intelligence in healthcare system

infections. As shown in above figure 3, it had issued a warning to WHO regarding this pandemic but that time not many people believed that the scenario could become this much dangerous. That time people though that how contextual factors can claim a disease turn into an outbreak. So data analysis play an important role in predicting the next levels of danger we our society can face. Alibaba, the e-commerce giant has developed an artificial intelligence based system which can detect corona virus within 20 seconds with $96 \%$ accuracy, which takes human a minimum time of 15 minutes. This system processes CT Scans of patient and gives $96 \%$ accurate result. Now over 100 of clinics are using this technique as it's very important to increase the speed of test for getting cured earlier without staking life at risk. Iran and many other countries are using artificial intelligence images recognition to analyze CT Scans for corona virus testing.

B. 3D Printers: As we know that for the treatment of COVID-19 patients, ventilators are needed but the problem is that, equipment and patients ratio differs a lot but if the patient's treatment is not provided on time then it may cause the patient's death shortly. So many technical professionals all over the world have combined together in printing ventilators using $3 \mathrm{D}$ printers and they are given to hospitals and clinic for the treatment of COVID-19 patients. 
C. Hong Kong's train cleaning robots: - Now a day trains in Hong Kong are using Vaporized Hydrogen Peroxide robots to disinfect whole trains as shown below in figure 4 .

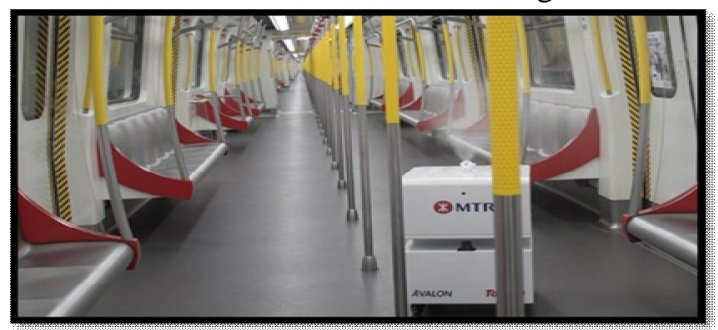

Figure 4: Train sanitizing intelligent equipments

As trains carries many passengers daily and if these trains would not be disinfected then it might become a breeding ground for spread of viruses. These robots are expert in deep cleaning and reach every corners of the train where human hands can't reach. These robots are approved and well tested by the company.

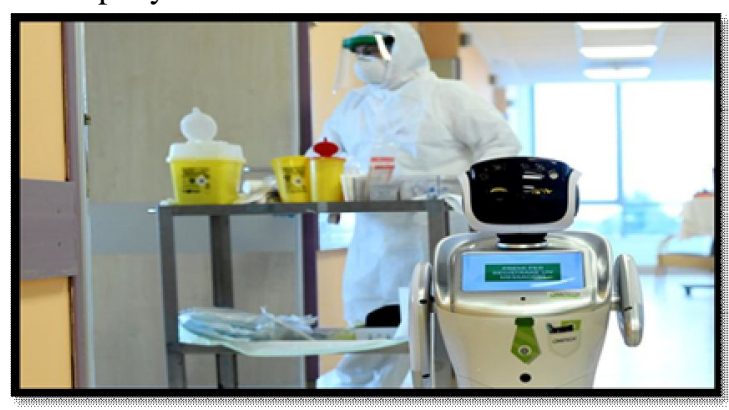

Figure 5: Robotics in healthcare monitoring

Figure 5 shows the robots are also used in this mode to disinfect those residential areas where COVID-19 patients were living, so that spread could be minimized and thus, making those place safe for other people.

As per the company, it takes almost 15 minutes to disinfect a room and it can kill many bacteria along with corona virus. It can also deactivate the virus by $99.9 \%$. Hong Kong is in process of testing Nano air filtration to improve air qualities and disinfect the air so that spread of virus through air could be stopped. Robots are also being used to assist the COVID-19 patients in many hospitals all over the world. At Cambridge university, the researchers have tested many household materials that we generally use, to suggest the best material available at home which can be used for making mask at home for maximum protection and as per the research, the vacuum cleaner bags are $95 \%$ effective in providing security against viruses and dish towel is $83 \%$ effective. So that people who don't have mask can make homemade mask for themselves using these materials for more effectiveness. A lab in Pune has developed India's first Indigenous COVID-19 testing kit. It has been developed by MyLab discovery solution. Cost of a single kit is 80,000 rupees and one kit can be used to test 100 patients. Drones are also being widely used for monitoring those areas and people who are under quarantine.

\subsection{Other daily applications and working:}

In this situation where social activities and meetings can't be organized, as the government has announced lockdown in many countries and all schools, offices and other organizations are close, everyone is forced to be at home for the sake of life and security. In this scenario people are shifting toward a new life style and mobile phone communication and applications are pillar behind this change.

Though we are locked inside our rooms but we are not helpless, we are doing everything we used to do; the difference is only that the medium has been changed. Our mobile phone is very useful in this.As mobile phones are available in almost every hands [13], it has become the main source of knowledge, educations, communication, employment, etc.

Some of the mobile applications which are being heavily used to lead a normal life during COVID-19:

I. Microsoft Teams: It is free application easily available on Google play store. There are so many things and works which can be done from home as shown in figure 6 , it has various excellent features like:

a. Many people can join together for a meeting.

b. We can record the meeting for future use.

c. Good audio and video calling experience.

d. Can share files and media.

e. It is highly customized.

f. Security is better than other similar apps.

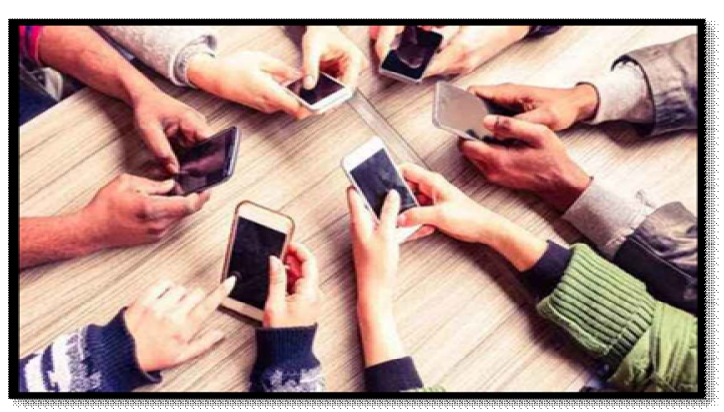

Figure 6: Everything on your finger tip

II. Education: The main concern was the education of children which was in danger but application like Teams, zoom etc. have solved this problem. These applications help in creating a virtual classroom with the advanced facilities like whiteboard, power point presentation and other file sharing. Teachers are able to teach in same manner as they used to do earlier in real classroom and giving assignment and can see the progress of their students. We can say that our mobile communication and networks are boon for us because 
it has managed the education of billions of students in a great manner. The best part is audio and video calls are of good qualities and teachers can give full attention to the whole class because virtual classes don't face the problem of back benchers so every student is equal here. These learning applications are easily downloadable, and can be used like image is shown below in figure 7 .

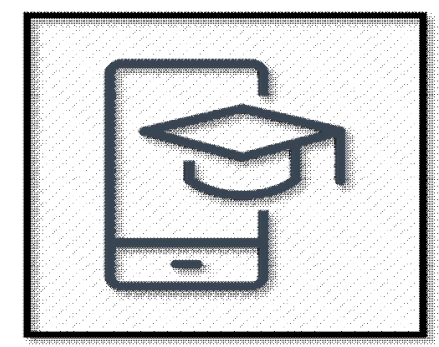

Figure 7: Learning applications in mobile phone

Teachers can also organize parent-teacher meetings if needed and also regulate other management works. Almost all schools, colleges and institutions are using these apps to impart education.

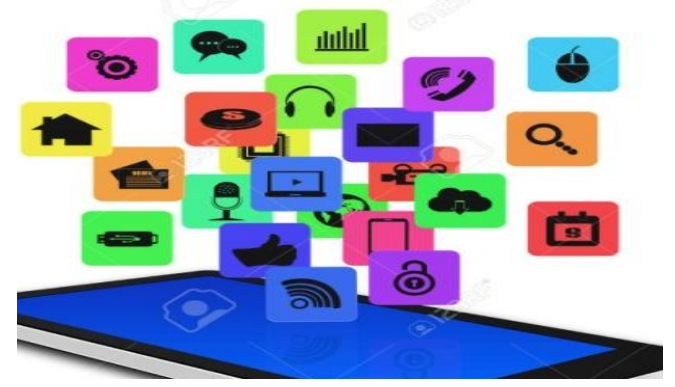

Figure 8: various applications of mobile technology

III. Employments: These days many offices are regulating their works online to the best possible extent. Figure 8 presents that there are so many application which are not only the source of entertainment but it is also supporting our economy by facilitating best possible platform needed to run various organizations. Many companies are making best use of technologies for its operations. Group meetings are being organized to discuss the issues and accordingly tasks are allotted to all employees are in these way they are working.

IV. Video conferencing and interfacing: As we have many apps for video calling like WhatsApp, Google Duo, etc. but they allow limited participants but zoom allow up to 100 people at a time so that many people can be contacted a time. As most places are in lockdown state so video calling is the best way to keep in touch and it give a feel of being together in this pandemic.

Video Conferencing cloud: As shown in figure 9, there are free mobile app easily available on Google play store which provides free HD meeting with quality video and voice calling and facilitates mobile sharing for up to 100 people at a time. It provide platform for online meetings, training, video webinar, conference rooms, chats and phone system. According to the New York Times, this app was downloaded by more than 600000 users in just one day during the start of lockdown which defines its importance. Online concert, seminars and workshops: as all the shootings and clubs are closed, at many places online concert are being organized to maintain the source of Entertainment and joy. Many institutions are organizing online workshops and seminar for those who want to learn something new and so they can utilize their 24 hours in meaningful way. Birthdays and anniversaries are also being celebrated on zoom with all family members at many places all over the world.

V. Fitness: Yoga and exercise are also being taught to people every day on time through these apps so that people can stay fit and healthy in their home. Online social gathering: there are many social gatherings taking place online through these apps like family gathering, friends gathering, religious gathering, etc. Many people come together for religious discussion every day and they talk on various topics just like offline "prawachan" which is best used by old people.

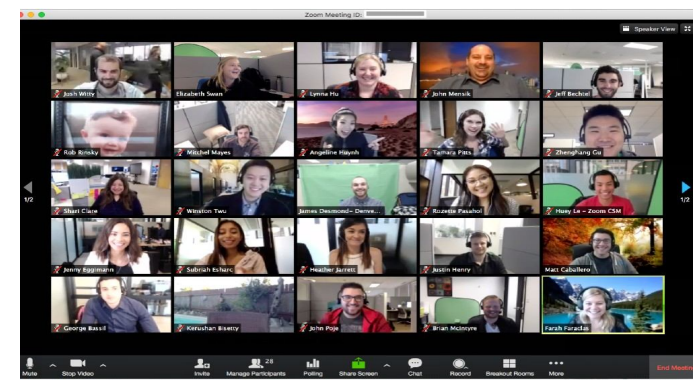

Figure 9: Video conferencing using technoogy

VI. Shopping and availability of utilities: Many apps like Big Basket, DMart, Grofers, Swiggy, etc. which are also easily available in play store, are playing a big role in serving people in this tough situation so that people can stay at home safely without worrying about how to buy groceries and ordering food online. These apps works smartly in taking orders of groceries and delivering them on time to the door step of our house without bothering anyone to come out of their homes.

VII. Payment Gateways like Google pay and Paytm: The online payment apps like Google pay, paytm, paypal, UPI, phone pay, etc., are free apps easily available on Google play store, are very important platform for online money transactions. Using gateways as shown in figure 10 , money is being transferred from one account to another account. 


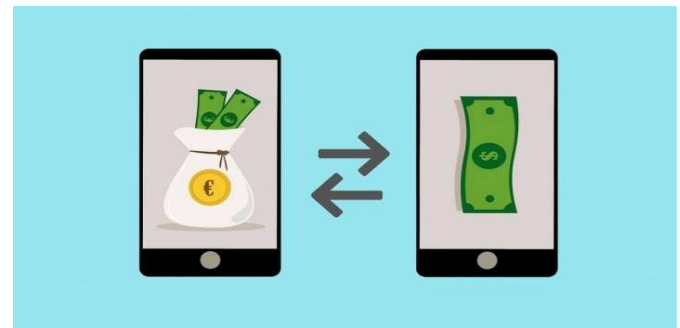

Figure 10: financial balancing using networking

We can easily pay our bills for our online shopping; we can also transfer money to our relatives in need without rushing to banks, safely from home. Moreover we can pay our electricity bills; we can order our cooking cylinders via a simple phone call as well as pay its bill through these apps. As phones are very necessary for making calls and using data pack for all facilities we are talking about so we don't need to wait for the recharge even at mid night as these apps are very convenient for our phone data recharge. Other facilities are like we can check our bank statement and transactions without stepping out of our home on phone only. We can help needy people by donating money and that's also through app on phone. Mobile phone and communication has made this hard time very simple and it has helped a lot in leading normal life. Many of these apps like Paytm and Google Pay have a separate portal for common people who want to donate money to right place so that our government can utilize those funds to help needy people.

VIII. Online Treatment and medicines: These are mobile phone free apps like Med life, Pharm Easy, and Net meds easily available on Google play store. In the below figure 11, these apps are very useful during lockdown as people can't afford to stand in crowd, staking their life at risk before medical store for purchase of medicines. These apps take the responsibilities to deliver the exact ordered medicines sincerely on time without fail. We can also order our medicine by making a simple call on phone.

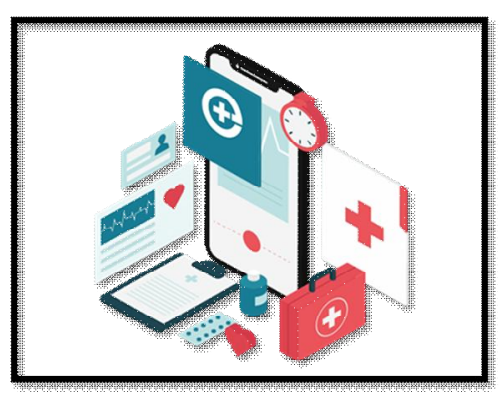

Figure 11: Online Treatment and medicines

\section{Open Platforms for Online education/} Entertainments: as during COVID-19 we need to make social distancing and stay more at home. Despite of these issues we people are utilizing their time very wisely in learning new skills and technical courses. Almost everyone have mobile phone and internet and here the new starting begins, we have plenty of learning apps and informative sites like W3school,Greeks for Greeks, udemy, unacademy, IASbaba, Cambly etc. there are thousands of learning apps and websites which come with numbers of courses that anyone would love to learn. Some of them are free and some charges money for each courses but the learning which they provide are very time worth. These learning platforms like e-learning platform shown below in figure 12 are open to all and very meaningful.

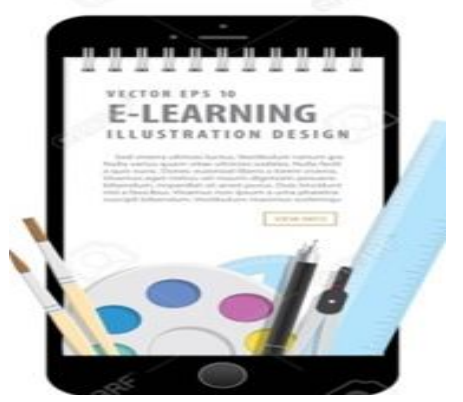

Figure 12: student oriented things at one place

Other skills which we can learn through internet and you tube are dancing, painting, art and craft, hacks, different languages, playing instruments, cooking etc. Social media apps like Face book, Instagram, WhatsApp, Twitter, etc. are also successful in keeping people engaged on social media platform. People can easily talk to each other and get help and also learn many skills. All these apps keep us updated about our surroundings and current affairs.

X. Aarogya Setu app: Our Prime Minister Modi, in his recent address to the nation has extended the lockdown till $17^{\text {th }}$ of May. He has advised every citizens of India to download this Aarogya Setu application shown below in figure 13 , as this application is very useful for everyone.

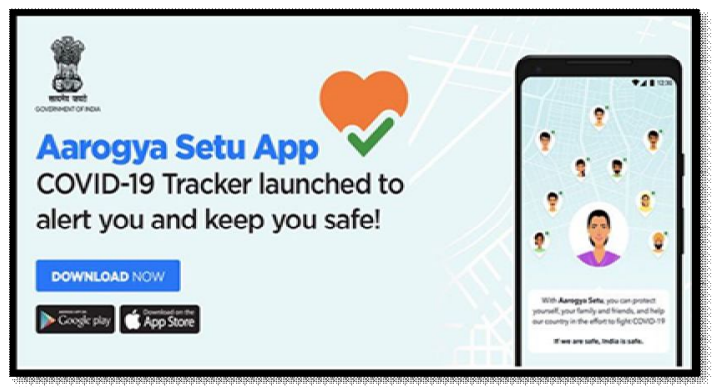

Figure 13: tracker to alert people

Features \& Working:

This application has been developed by government of India and it deals with ongoing corona issues. Aim of this app is to alert people if they are in contact with any COVID active patient, and also telling people about best practices in this situation. It informs people about relevant advisories regarding safety and security against virus. This app is for 
every citizen of India, it's free and easily available on Google play store.

This app tracks our current location and uses Bluetooth of our mobile phone and whenever we come in hotspot area or if we come in contact with any infected person unknowingly then this app inform us by sending us notification so that we can immediately get alert against the deadly virus. This feature of this application is life savior as it alerts us and protects us from virus and infections of COVID-19. Its working: it's a very simple app and anyone can use it. Actually when anyone download the app, then some basic information is asked like name, gender, and city, age, whether the person is affected or have any symptoms of COVID-19, any recent tour to abroad, etc. This simple app can save our society from further infection, if we fill our information correctly and if everyone download and use this application.

XI. Gaming apps: As children and youth as well as older have many platform to learn in home through their mobile phones but to refresh themselves they need some interesting games to play but neither they can go outside their houses to play nor everyone can afford expensive video games. But this is also nothing to worry about. As there are many free, and very interesting games like MPL, Candy Crush, PUBG, LudoKing, Qureka, Temple Run, and many more games are easily available in Google play store and can be downloaded in a fraction of time. Some of these games reward its winner with real cash money and thus making it much more interesting that user don't miss outdoor games. So in this manner again our mobile has proved to be sufficient tool during COVID-19.

XII. Online jobs: Due to COVID-19 many people are becoming jobless in a sense as our economy is falling down but expenses never falls down so to support the family, in free time people can do part time jobs to earn money. There are many job platforms like Upwork, Meesho, Topal, Guru, Truelancer, SquadRun, WIX etc. if they are good in their field there are lots of opportunities to earn a good amount of money.

Other source of entertainment are various apps like Netflix, YouTube, Jiocinema, Amazon's Prime videos, Tik tok, Hotstar and many more are there. Some of these charges money and others are free. All of these can be easily downloaded in phone. These apps contain many latest Hollywood and Bollywood movies and many interesting web series. These are best source of entertainment during lockdown.

XIII. Monitoring System App: Public Health and Family Welfare Department of Telangana's Government has launched a real time application which is useful in tracking and monitoring corona patients. Its prominent features are: It allows its workers to monitor and manage over 50,000 calls and asked queries. These queries and calls will be analyzed and it will ensure that all corona active people are well isolated and their treatment is being done properly avoiding its further spread. Apple and Google are also making a corona virus tracking system for iOS and android this is a good step to fight against the COVID-19.

\subsection{G and COVID-19}

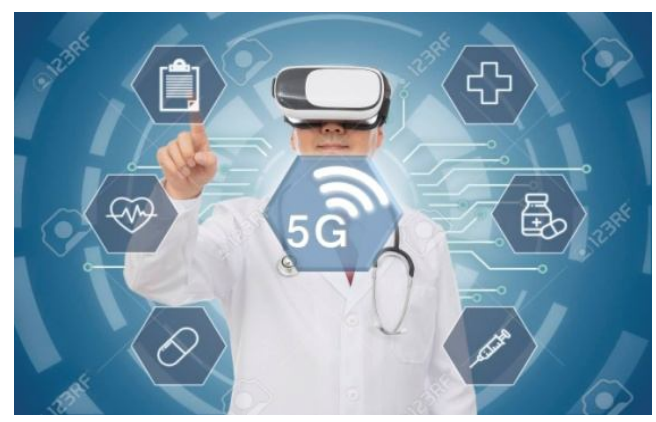

Figure 14: 5G and COVID-19

Does 5G triggers COVID-19?

British ex-footballer David Icke in an interview to London real TV channel claimed a link between 5G and COVID -19 outbreak mentioned in above figure 14, as per his conspiracy theory he revealed the fact that $5 \mathrm{G}$ poisons the our cells due to electromagnetic fields but this claim is false. He also claimed that corona virus breath a new life in $5 \mathrm{G}$ wireless service and Wuhan rolled it so just after rolling of $5 \mathrm{G}$ service Wuhan witnessed COVID-19 outbreak but again this claim has been proved wrong because WHO and arm of United Nation has found that 5G affect human lives [14-15].

The Diagnosis of COVID-19 patients using 5G is already in news for few days. Chinese doctors do diagnosis of corona patients using 5G technology in China for the very first time. Chengdu, a city in China used 5G technology for diagnosis of corona patients successfully using remote control CT Scanners. As per the doctors, computer screen show scans of patients in a hospital over 700 kilometers away via remote diagnosis. A CT Scan and a nucleic acid test are required for this diagnosis.

\section{CONCLUSION}

As in this situation also we are able to operate our each and every basic life functionality, mobile communication and technologies have played a great role in this. We are doing everything we used to do before pandemic outbreak with the help of phone and technologies. Due to technical support which we are getting through our mobile communication we are able to live a normal life. Our mobile opens a door to digital world where we get many important services like education, employment, money transfer, bill payments, purchasing of groceries and medicine, game, etc. our technologies are protecting us from virus and also helping in treatment of corona patients. Scientists and researchers no longer have geographical boundaries and the world is using its all top recent technologies for people's health and security. 
So along with all these facilities we should try to take care of us in best possible ways. Finally the impact of various technologies have been discussed in depth, also how mobile technology influencing our future generation in so many ways.

\section{REFERENCES}

1. A. Haleem, M. Javaid, Vaishya Effects of COVID 19 pandemic in daily life Curr Med Res Pract (2020), 10.1016/j.cmrp.2020.03.011.

2. H. Luo, Q.L. Tang, Y.X. Shang, S.B. Liang, M. Yang, NRobinson, J.P. Liu A review of historical classics, research evidence and current prevention programs Chin J Integr Med (2020), 10.1007/s11655-020-3192-6

3. Q. Ruan, K. Yang, W. Wang, L. Jiang, J. Song Clinical predictors of mortality due to COVID-19 based on an analysis of data of 150 patients from Wuhan, China Intensive Care Med (2020 Mar 3), pp. 1-3

4. S.F. Ahmed, A.A. Quadeer, M.R. McKay Preliminary identification of potential vaccine targets for the COVID-19 coronavirus (SARS-CoV-2) based on SARS - COV immunological studies Viruses, 12 (3) (2020 Mar), p. 254.

5. World Health Organization (WHO) Coronavirus disease (COVID-19) advice for the public https://www.who.int/ emergencies/diseases/novelcorona virus - 2019/ advice- for-public2020.

6. M. Ienca, E. Vayena On the responsible use of digital data to tackle the COVID-19 pandemic Nat Med (2020 Mar 27), pp. 1-2.

https://doi.org/10.1038/s41591-020-0832-5

7. M. Sarwar, T.R. Soomro Impact of smartphone's on society Eur J Sci Res, 98 (2013), pp. 216-226.

8. K. Gelles, G. Petras How ventilators work and why COVID-19 patients need them to survive coronavirus USA Today (2020) accessed 11th Apr 2020.

9. Nawaz, Nishad, Artificial Intelligence Interchange Human Intervention in the Recruitment Process in Indian Software Industry (2019). Volume 8, No.4, July - August 2019 International Journal of Advanced Trends in Computer Science and Engineering (IJATCSE). SSRN: https://ssrn.com/abstract=3521912 or http://dx.d oi.org/10.2139/ssrn.3521912

10. Allocating ventilators in a pandemic (accessed March 24, 2020) https://healthmanagement.org/ c/ icu/news/ allocating - ventilators-in-a-pandemic (2020).

11. A. Haleem, R. Vaishya, M. Javaid, I.H. Khan Artificial Intelligence (AI) applications in orthopaedics: an innovative technology to embrace J Clin Orthop Trauma (2019), 10.1016/j.jcot.2019.06.012.

12. G. Manogaran, C. Thota, D. Lopez, R. Sundaraseka Big data security intelligence for healthcare industry 4.0. Cyber security for Industry, 4.0, Springer, Cham (2017), pp. 103-126.
13. Kumanan Wilson Mobile cell phone technology puts the future of health care in our hands Can Med Assoc J, 190 (13) (Apr 2018), pp. E378-E379.

14. S. Byun, (2019), Gateway-based Resource Control for Reliable IoT Environments, International Journal of Advanced Trends in Computer Science and Engineering (IJATCSE) Vol. 8, No. 5, PP. 1881-1885. https:// doi.org/ 10.30534/ijatcse/2019/11852019.

15. I. Chih-Lin, Shuangfeng Han, Zhikun Xu, Qi Sun, Zhe ngang Pan 5G: rethink mobile communications for 2020

Philos Trans Roy Soc A (2016.Mar6), 10.1098/ rsta. 2014.0432374 .20140432$. 